\title{
Linking urban design to sustainability: formal indicators of social urban sustainability field research in Perth, Western Australia
}

\author{
Sergio Porta ${ }^{1 *}$ and John Luciano Renne ${ }^{2}$ \\ ${ }^{1}$ Dipartimento di Progettazione dell'Architettura, Politecnico di Milano, Facoltà di Architettura Civile, \\ via Durando 10, 20168 Milano, Italy \\ ${ }^{2}$ Planning and Transport Research Centre, Murdoch University, South Street, Murdoch, \\ Western Australia 6150, Australia
}

The making of a livable urban community is a complex endeavor. For much of the 20th Century planners and engineers believed that modern and rational decision-making would create successful cities. Today, political leaders across the globe are considering ways to promote sustainable development and the concepts of New Urbanism are making their way from the drawing board to the ground. While much has changed in the world, the creation of a successful street is as much of an art today as it was in the 1960s.

Our work seeks to investigate 'street life' in cities as a crucial factor towards community success. What are the components of the neighborhood and street form that contributes to the richness of street life? To answer this question we rely on the literature. The aim of the Formal Indicators of Social Urban Sustainability study is to measure the formal components of a neighborhood and street that theorists have stated important in promoting sustainability. This paper will describe how this concept helps to bridge urban design and sustainability. It will describe the tool and show how this was applied in a comparative assessment of Joondalup and Fremantle, two urban centers in the Perth metropolitan area.

URBAN DESIGN International (2005) 10, 51-64. doi:10.1057/palgrave.udi.9000136

Keywords: sustainable; street; indicators; social; Australia

\section{Formal indicators concept: a bridge between urban design and sustainability}

Face-to-face human interactions on the stage of public life are extremely relevant for supporting livability, safety and control, economic development, participation, and identity (Jacobs, 1961; Goffman, 1963, 1967; Lemert and Branaman, 1997). Many researchers like Oscar Newman, William Whyte and Jan Gehl focus their research on the observation of people in real-life situations to determine how the built environment impacts social wellness (Newman, 1973; Gehl, 1987, c. 1980; Whyte, 1988). The results of their studies helped guide designers to rethink the impact of their plans upon real life. For example, Oscar Newman's studies led to the call for 'defensible space' to help create a safe environment.

The recent sustainability agenda has called for the integration of economic, environmental, and social concerns when planning future development. The problem for urban designers is where does the design fit into sustainability? Design can promote and/or hinder economic, environmental, and social processes. Indicators must be created to quantify the formal components of the design in order to determine the impact upon the level of sustainability. The formal indicators concept helps to bridge urban design and sustainability because it allows for the design of streets and neighborhoods to be measured and compared. The concept 
of sustainability is only useful if we can gauge the impact of development upon the economy, the environment, and the wellness of the community. Does the design of streets and neighborhoods encourage more people to walk or drive? What, in particular about the design, promotes this activity? The Formal Indicators Concept seeks to quantitatively measure graphic representations of spaces to provide answers to these questions? The results of our research allow for both a systematic assessment of existing urban settings (analysis) and measurement of plans to compare different alternatives.

This concept is useful because it allows planners and designers the ability to breakdown the design of a street and/or neighborhood to determine the positive and negative attributes. This is a tool and does not prescribe what is 'good' or 'bad' design but it helps for a local discussion to define 'good' and 'bad'. This enables a bridge between urban design and sustainability because now the measurements taken can be applied to factors of sustainability, framing the debate on the city form, at the micro level, within a Sustainable Development Indicator (SDI) environment. Planners will benefit because they can evaluate the streets in their cities that are most successful and use this tool to help invigorate streets that are not by understanding where the design fails. While social outcomes are not dependant solely upon design, it is difficult for a street to be successful if it is poorly designed.

\section{How to use the tool}

The formal indicators concept is based on the representation of spaces. The first step in the process is to define how to represent the space and the second step is to measure the representation. The representations used are: plans, bird-eye views (ie photographs), and sections. This study utilized two types of indicators: urban fabric and street indicators. Next, this section will use the results of the field research in Western Australia in order to define each indicator. The field research has been carried out by a team work which included Erik Stanton-Hicks, Daniel Colgan, and Sarah Bolitho at the ISTP, Institute of Sustainability and Technology Policy, Murdoch University in Perth, WA; Juliette Louis processed all quantitative information.

\section{Urban fabric indicators}

Developed by the Western Australia Ministry for Planning, urban fabric indicators measure the scale of the district or the neighborhood. Underpinning the development of these indicators is the assumption that 'traditionally' designed town centers or suburbs are more sustainable in respect to social equity, economic stability and the protection/enhancement of the environment, compared to 'conventionally' designed places. Traditional suburbs are defined as 'A center with either a 400 to 800 meter radius that has a range of community facilities, a mix of housing, substantial local employment as is linked to other suburban centers by public transport. It has a safe, attractive and well-defined public realm of interconnected streets fronted by buildings, and a well-used public open space...' (Ministry for Planning, 2001).

Eight urban fabric indicators were used including: accessibility (pedsheds), land use diversity, pub$\mathrm{lic} /$ private realm, natural surveillance (fronts and backs), permeability/street connectivity, employment density, number of buildings, and number of lots.

\section{Accessibility (Pedsheds)}

The mapping of a 'pedshed' or walkable catchment enables an assessment to be made about the interconnectedness and accessibility of the street network for pedestrians. To map the pedshed, a 400- and/or 800-m circle is drawn around a transit stop which assumes a 5- and 10-min walk, respectively. The pedshed shows the percent of the circle that is truly accessible based on safety, sidewalk connectivity, and street layout. As seen in Figure 1, Fremantle is substantially more walkable than Joondalup.

\section{Land use diversity}

This indicator measures the variety of land uses within the walkable catchment area. A high value of diversity may increase consumer choice a greater degree for maintaining an urban lifestyle without increasing the need for motorized movements. Traditional developments should have a higher level of land use diversity than conventional developments. Fremantle performs remarkably higher than Joondalup especially for retail and the fine-grained diffusion of diverse landuses. 

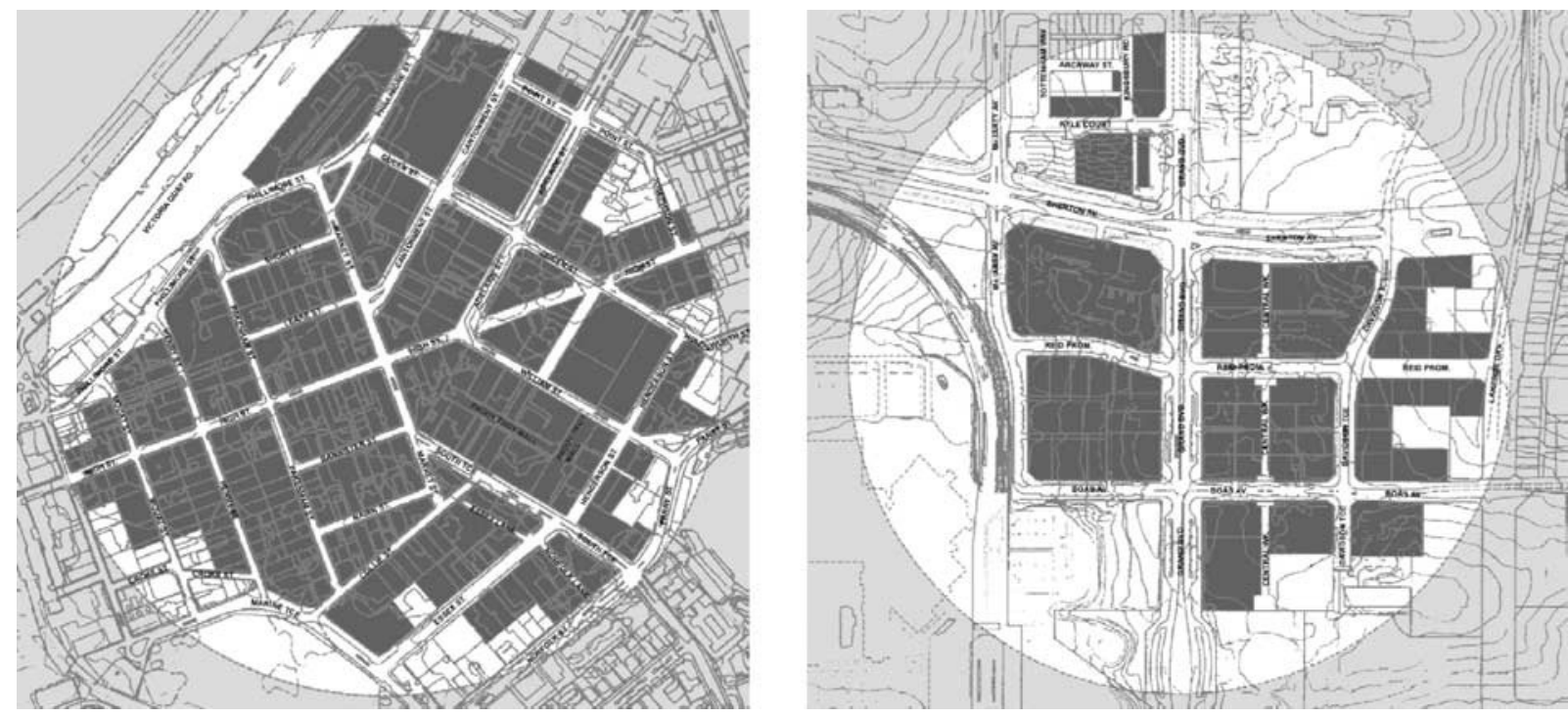

Figure 1. Urban fabric indicators: pedshed maps of Fremantle (left, $52 \%$ coverage) and Joondalup (right, $29 \%$ coverage).

\section{Public/private realm}

Public realm mapping identifies where the public can or cannot go (where the public cannot readily access $24 \mathrm{~h}$ a day). Areas in the public domain are places that individuals are free to go to at any time and may include public parks and open space, streets and sidewalks, and public parking lots. Mapping these areas gives an indication of how legible an area is in terms of coherence of urban form; that is, how easy it is for an individual to understand where to go and not to go in the city.

\section{Natural surveillance (fronts and backs)}

Natural surveillance provides an increased security for the pedestrian due to the feeling of 'eyes on the streets' (Jacobs, 1961) and enhanced capability of territorialization for inhabitants and users (Newman, 1973, 1996). Front and back mapping identifies areas of streets that have active building frontage, which helps to promote a better natural street surveillance (see Figure 2 and Table 1). Streets that are poorly designed with respect to this indicator contain blank walls, high fences, parking lots or the backs of commercial buildings.

\section{Permeability (street connectivity)}

The type and number of intersections in an area effects the movement by users in that given space and the user legibility of the street network
(Table 2). Four-way intersections offer both physical and visual directness of movement to a destination. T-junctions give a reduced choice in movement and force a change in direction. Culde-sacs are highly undesirable because they disrupt the flow of movement. To achieve a high level of permeability a street network should contain a high proportion of four-way intersections, few cul-de-sacs, and small street block sizes.

\section{Number of buildings and number of lots}

These final urban fabric indicators help to give an indication of the scale of the measurement area. Resulting figures show that different street layouts generate quite different performances as for both the number of stand-alone buildings (96 in Fremantle, 69 in Joondalup) and the number of lots (354 in Fremantle, 87 in Joondalup).

\section{Street indicators}

These indicators help to isolate the individual components that as a whole either add to or subtract from street vitality. This dissection will help planners to understand the building blocks of a successful (or unsuccessful) street. Whether the street is planned or built, these indicators can be used to improve the vitality of a street.

This study measured existing streets in Fremantle and Joondalup, Western Australia. Measurements 

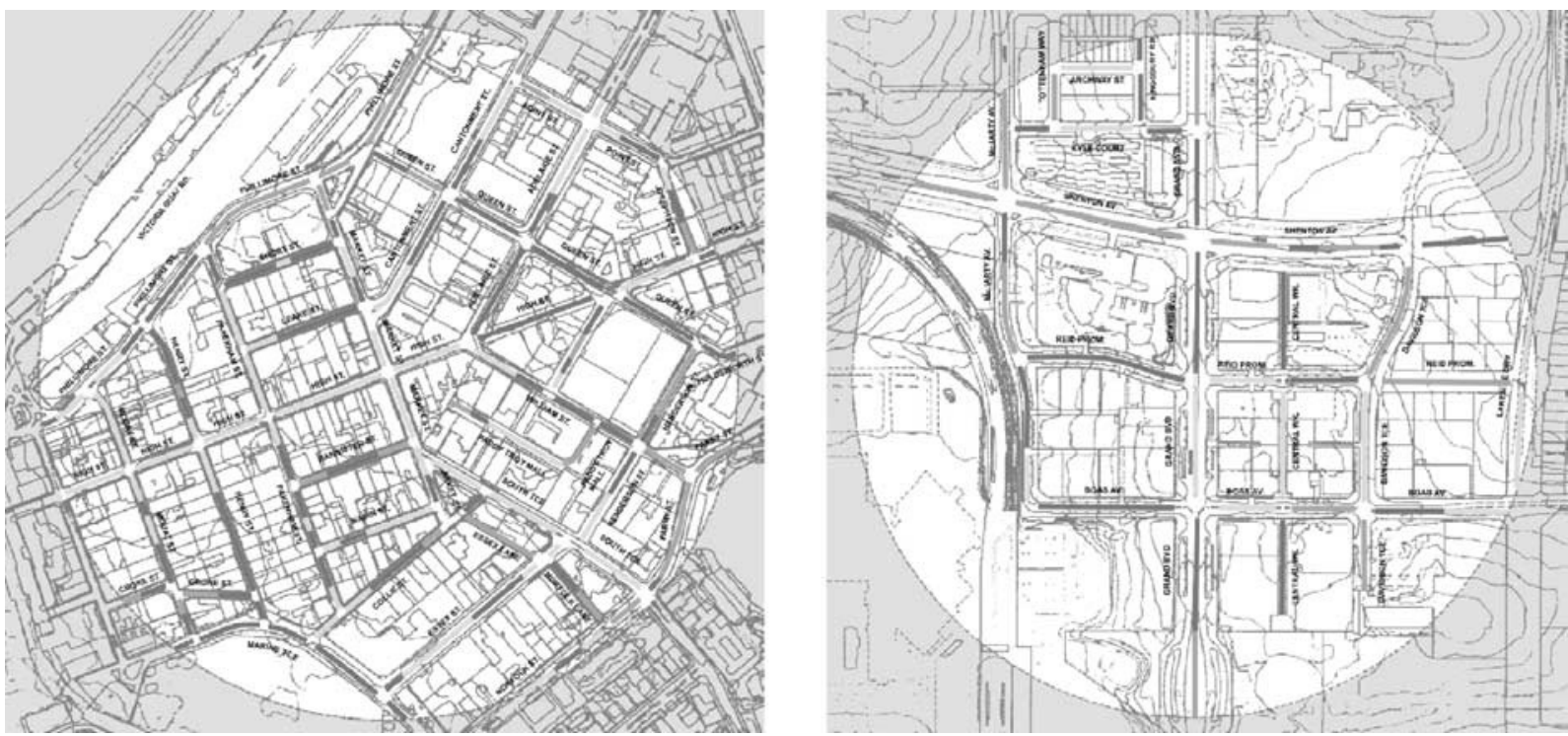

Figure 2. Urban fabric indicators: 'front and back' maps of Fremantle (left) and Joondalup (right).

Table 1 Urban fabric indicators: 'front and back' measurement

\begin{tabular}{|c|c|c|c|c|c|c|c|}
\hline & \multicolumn{2}{|c|}{ Fronts on fronts } & \multicolumn{2}{|c|}{ Fronts on backs } & \multicolumn{2}{|c|}{ Backs on backs } & \multirow{2}{*}{$\frac{\text { Total }}{\mathrm{m}}$} \\
\hline & $\mathrm{m}$ & $\%$ & $\mathrm{~m}$ & $\%$ & $\mathrm{~m}$ & $\%$ & \\
\hline Fremantle & 2451 & 36.5 & 2874 & 42.8 & 1386 & 20.7 & 6711 \\
\hline Joondalup & 1029 & 26.0 & 1512 & 38.3 & 1409 & 35.7 & 3950 \\
\hline
\end{tabular}

The table highlights remarkable differences in terms of total amount of streets as well as their natural surveillance potential.

Table 2 Urban fabric indicators: street connectivity measurement

\begin{tabular}{lrccc}
\hline $\begin{array}{l}\text { Intersection } \\
\text { type }\end{array}$ & Number & $\begin{array}{c}\text { Number } \\
\mathbf{( k m}^{\mathbf{2}} \mathbf{n}\end{array}$ & $\begin{array}{c}\text { Points } \\
\text { allocated }\end{array}$ & Score \\
\hline 4 Ways & 16 & 32 & 2 & 32 \\
F & 8 & 16 & & 16 \\
J & 29 & 58 & 1 & 29 \\
T Junction & 11 & 22 & & 11 \\
F & 1 & 2 & -1 & -1 \\
J & 3 & 6 & & -3 \\
Cul-de-sac & & & & 60 \\
F & 46 & 92 & & 24 \\
J & 22 & 44 & & \\
Total & & & & \\
F & & & & \\
J & & & & \\
\hline
\end{tabular}

were taken using photographs along the center of the street, $25 \mathrm{~m}$ apart. A camera was attached to a tripod at eye level to ensure that each photograph was capturing the same field of view. Once the photographs were developed, each photograph was analyzed to gather the measurements for the indicators including: sky exposure, façade continuity, softness, social width, visual complexity, number of buildings, sedibility, and detractors. Each photograph was scanned and a computer program was used to make precise measurements. The following section will describe each indicator and the method for measurement. Although this project used photos from existing streets, measurements could be taken from 'virtual' streets built in a 3D program. This could help planners to correct problems before the project is built.

\section{Sky exposure}

Sky exposure is the amount of sky visible in each photograph, where trees are considered as opaque, the same as buildings or other permanent man-made objects. This measurement seeks to understand the urban environments' ability to encapsulate the pedestrian. The designer can relate this information to the person's sense of intimacy through enclosure, their sense of 
livability (the street becomes like a living room), the sense of orientation and definition in space, and their sense of security.

To obtain the measurement, polylines were drawn in AutoCAD along the perimeter of the sky visible in each photograph. Areas of polygons were then automatically calculated and this number was inversed so that larger areas resulted in lower values in the database. Figure 3 represents streets with high, medium, and low values for sky exposure.

\section{Façade continuity}

Façade continuity is a measure of the continuousness of the building façade on a place that follows the line of sight. The continuity of building fronts adds to a sense of enclosure and definition of the public space. As such, this indicator could be seen
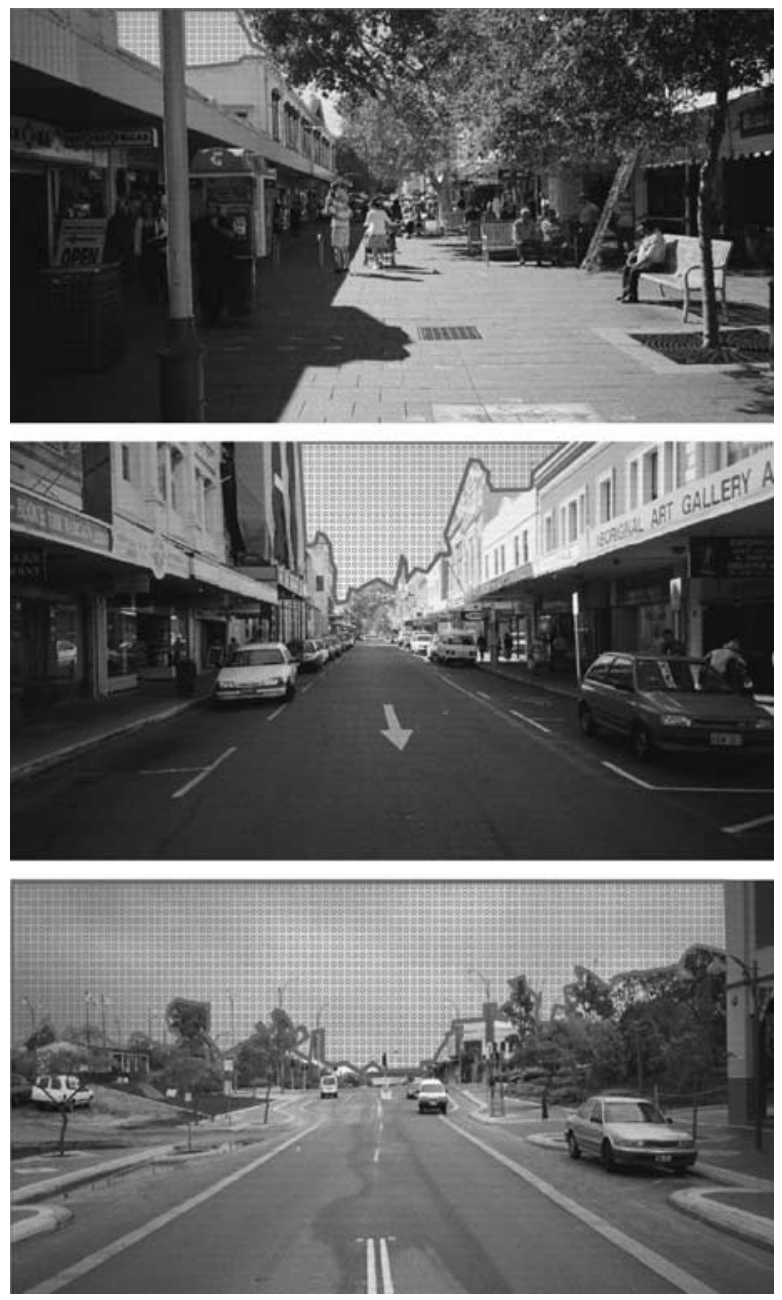

Figure 3. Street indicators: samples of sky exposure from the higher (top) to the lower (bottom). in close relationship with the sky exposure indicator, as a component of street intimacy. This indicator also examines the building fronts as a precondition for establishing a good relationship between the private space and the public space of streets. As such, this indicator describes the potential of a street scene to offer a sense of diversity. Using AutoCAD, this indicator was measured with a line drawn about $3 \mathrm{~m}$ above the ground for the whole portion of each street border. Next, polylines were created to identify the parts of the area between the ground and the top line that were discontinuous. Figure 4 depicts three examples of high, medium, and low levels of façade continuity.

\section{Softness (transparency and transitional space)}

Softness measures the subjective elements that make a street environment feel safe and welcom-
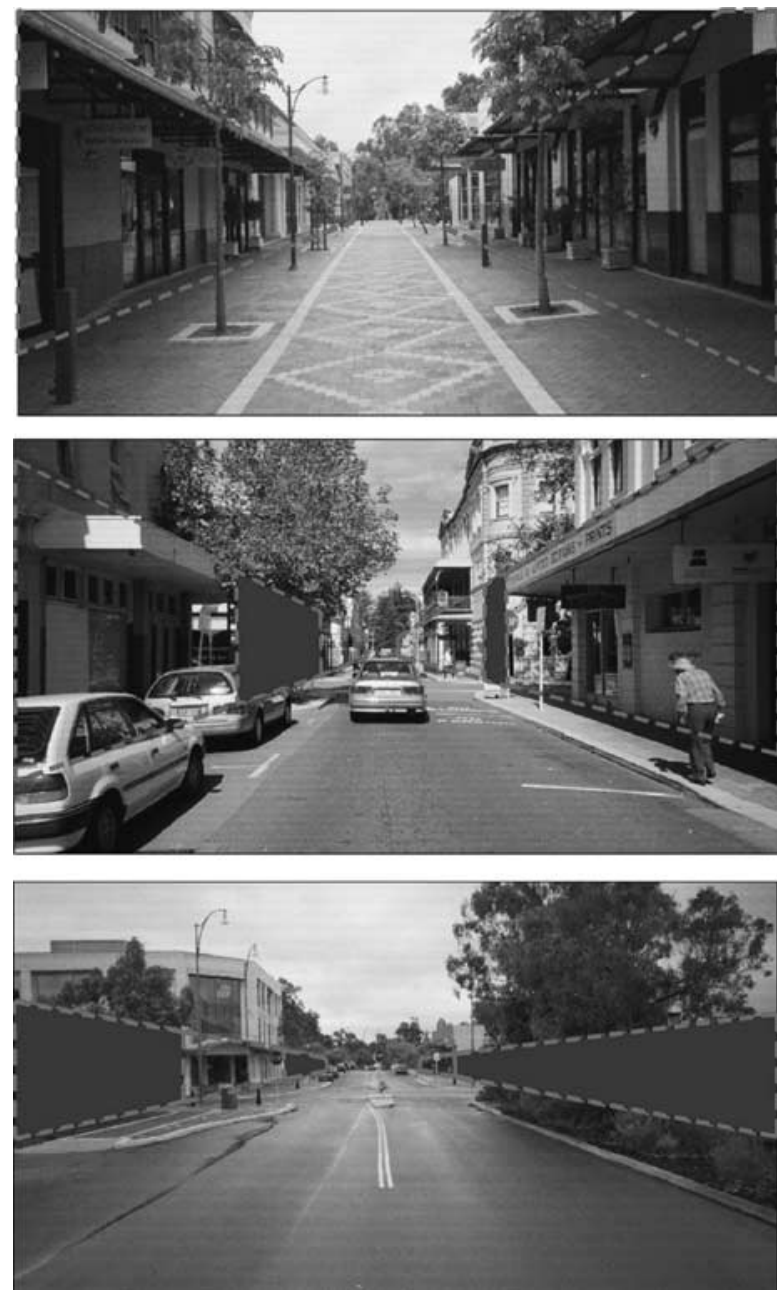

Figure 4. Street indicators: samples of Façade continuity from the higher (top) to the lower (bottom). 
ing. This is a compound indicator: its two elements are transparency and transitional space. Transparency is a measure of the amount of window space/area that fronts onto the street, allowing viewing into and out of the buildings. Transitional space is a measurement of spaces visually accessible front yards, stoops, porticos, verandas, shelters, entry setbacks, balcony awnings, or the like - that provide a 'soft' transition from the very private space to the public realm. Transparency and transitional space were measured independently and then averaged to get an overall measure for softness. In AutoCAD, polylines were drawn to define the presence of transparencies and transitional spaces and each were calculated. The total measurement was separately calculated for each of the two elements and then the average was taken. Due to the different nature of each sub-indicator, the data were normalized before calculating the average. Figure 5 shows examples of high, medium, and low ratings for softness.

\section{Social width}

Social width refers to the breadth of the street as it affects human interaction across the traffic area. This is a measurement of the restriction ('severance' effect) that traffic lanes and multi-functional lateral or median strips (parking strips, bike lanes, etc.) place on human interaction from one curb of a sidewalk to another. It also measures the interaction between people and activities taking place mainly at the ground floor of fronting buildings. Therefore, it is only the areas where humans cannot stand and interact that are measured. This indicator has been calculated based on personal judgment, according to the following criteria: Rating 5: Narrow pedestrian street or narrow one-way street that is open to traffic with or without parallel parking; Rating 4: Larger one-way street with parking on one side, a two-way street with one side of parking, or twoway street with no parking; Rating 3: A two-way street with parking on both sides (parallel or angled); Rating 2: A two-way street with a large median or lateral strip(s) and parking (parallel or angled); Rating 1: Two-way streets with four lanes (with or without a small median strip) and with or without parking (see Figure 6).

\section{Visual complexity}

Visual complexity is a measure of the amount of variety in the streetscape. It seeks to describe the
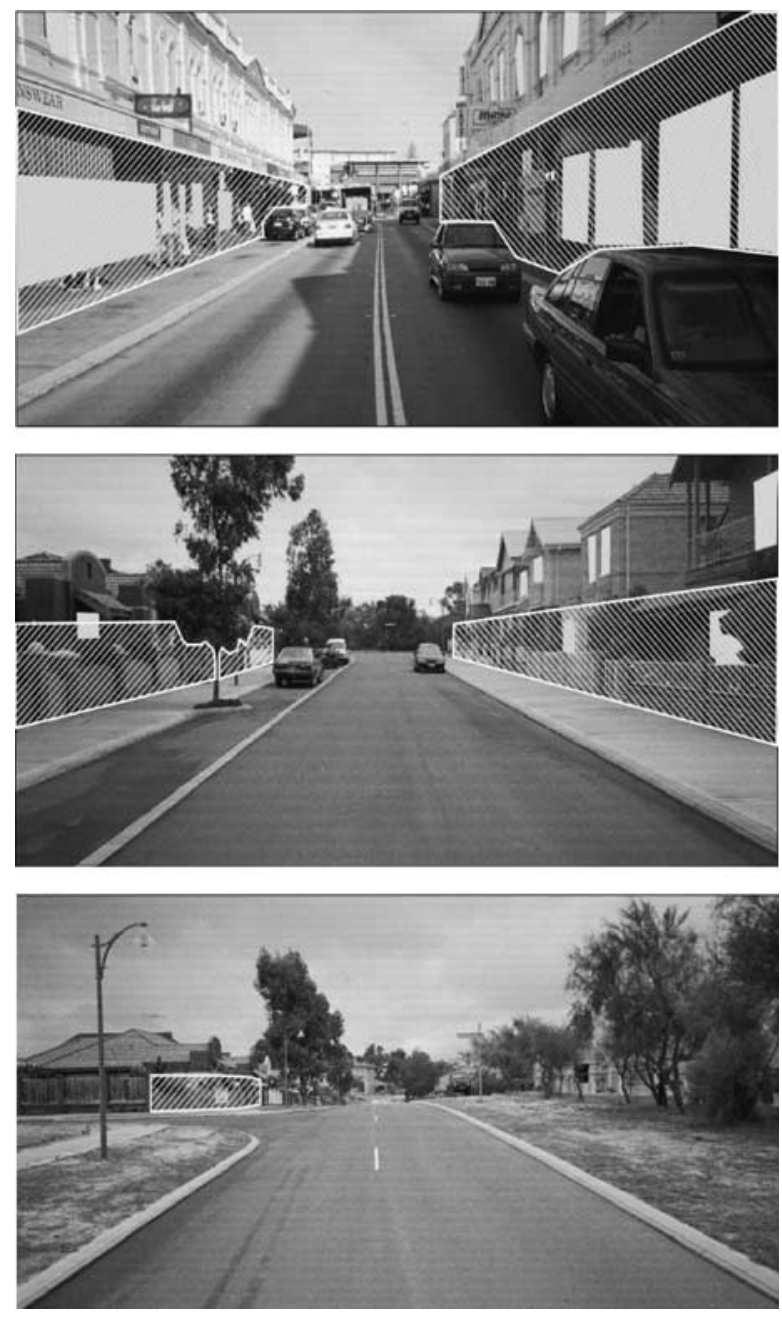

Figure 5. Street indicators: samples of softness from the higher (top) to the lower (bottom).

degree that the street is a rich visual tapestry. The particular multi-dimensional nature of a concept of 'visual variety' is best evaluated in four different sub-areas:

1. color (high contrast, brightness, richness, and the number of different colors);

2. façade (attractive fences, attractive height articulation and details in roof lines, balconies, verandas, and the number of different materials);

3. street furniture (seating, art, attractive lamp posts, raised planters, etc.);

4. street pavement (changes in texture, color, material, patterns, and attractive edging).

Similar to the social width indicator, visual complexity was also judged based on personal 

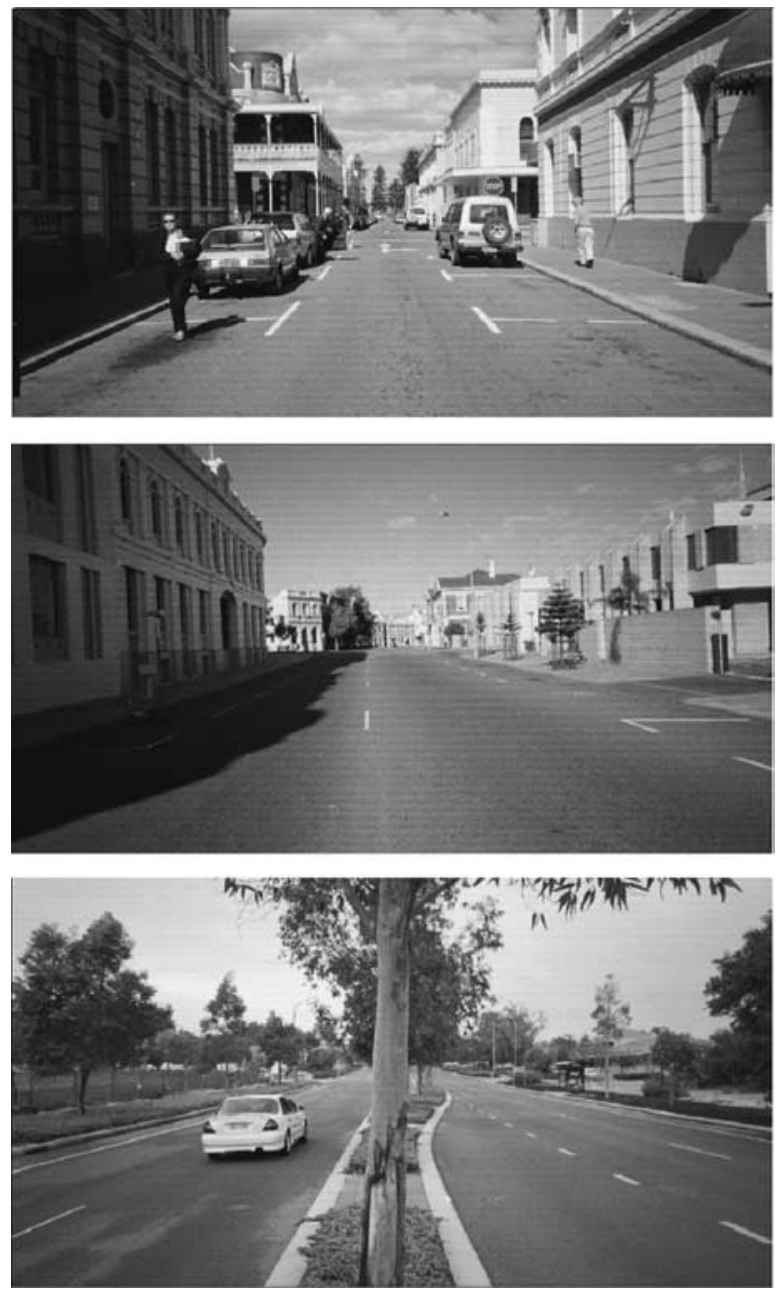

Figure 6. Street indicators: samples of social width from the higher (top, rating 5) to the lower (bottom, rating 1 ).

judgment. Each photograph was evaluated four times - one for each field - with reference to a 1-5 scale shown in Figure 7. The output was then calculated as the average of all four areas.

\section{Number of buildings}

The number of buildings refers to the apparent quantity of buildings visible in the pictures. It is a very simple measure of the 'scale' of the city, a factor which in many ways affects the street life, as many buildings often implies many entries, many windows, many different people and activities. The ratings for this indicator were divided into a scale from 1 to 5 shown below. Rating 5: 12 or more buildings visible; Rating 4: 9-11 buildings visible; Rating 3: 4-8 buildings
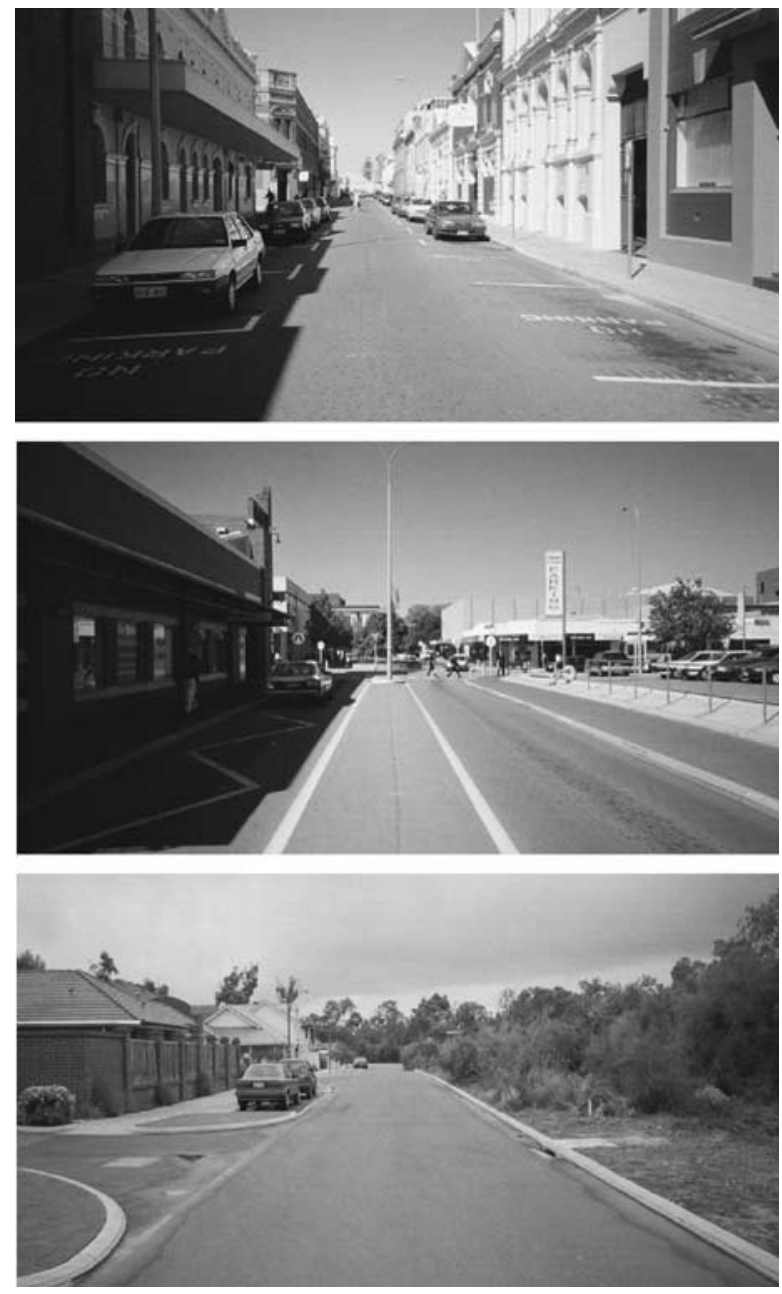

Figure 7. Street indicators: samples of visual complexity - from the higher (top) to the lower (bottom).

visible; Rating 2: 1-3 buildings visible; Rating 1: No buildings visible (see Figure 8 ).

\section{Sedibility}

William H. Whyte stated that 'sedibility' is the principle design factor in contributing to the social success of urban plazas in New York (Whyte, 1988). Sedibility is the measure of the number of seating opportunities visible in each photograph (ie benches, low walls, café chairs, etc.). To measure this, a distinction was made between primary and secondary seating. Primary seating constitutes objects made for people to sit on which include benches and chairs (moveable chairs were given a slightly higher rating). Secondary seating opportunities are objects not specifically made for the purpose of seating 

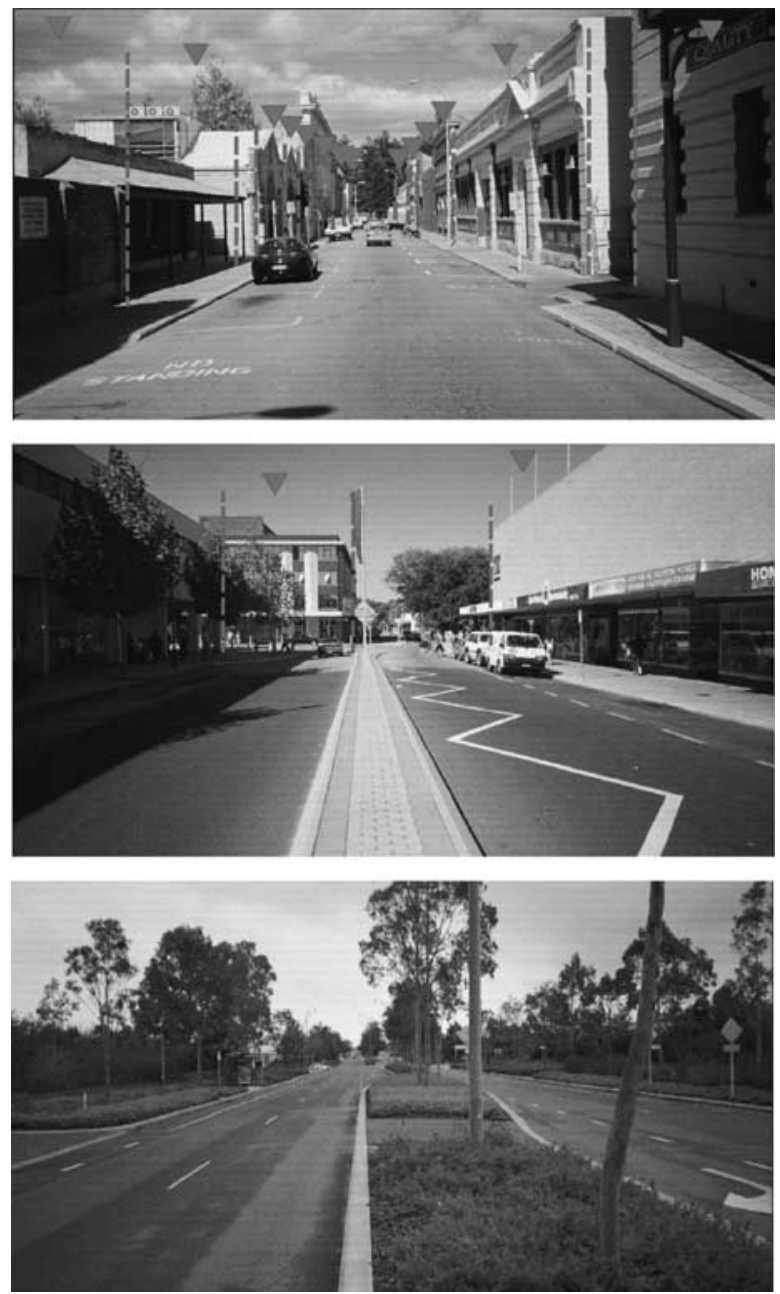

Figure 8. Street indicators: samples of number of buildings - from the higher (top, rating 5 ) to the lower (bottom, rating 1 ).

but on which people actually are very likely to sit on. This includes walls, stoops, fountain borders, ledges, planters, etc. Assessing the photographs, a scale from 1 to 5 was used, giving more weight to primary seating as shown below (see Figure 9). Rating 5: Continuous café strip, alfresco dining; Rating 4: Medium number of primary seating with or without other secondary seating; Rating 3: A small amount of primary seating or a couple of benches, or a lot of secondary seating; Rating 2: Some secondary seating with our without one bench; Rating 1: No seating.

\section{Detractors}

Detractors refers to any element that can be viewed as having a negative effect on the
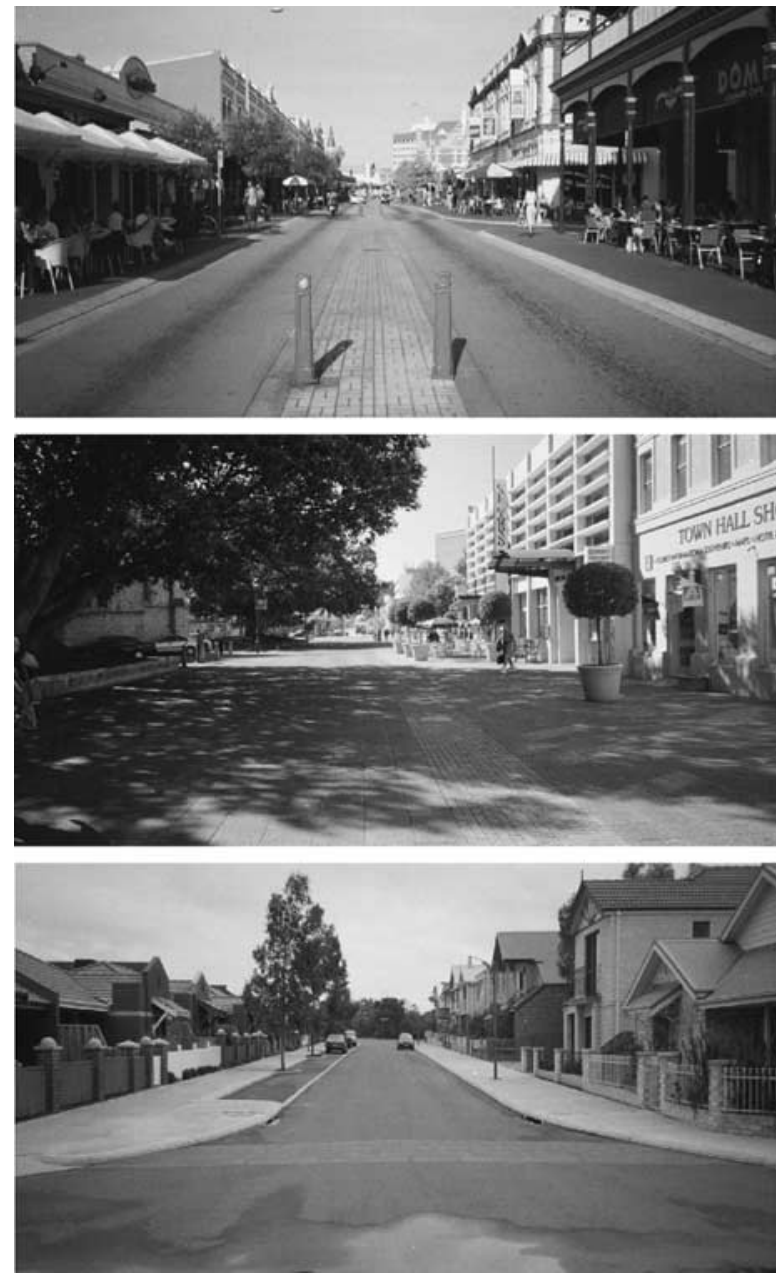

Figure 9. Street indicators: samples of sedibility - from the higher (top, rating 5) to the lower (bottom, rating 1).

streetscape potential to provide a good scene for the flourishing of urban social life. These have been broken down into three sub-indicators including: blank walls, aggressive automobile facilities, and rejecting objects. Blank walls are walls without windows, doors or other openings. Using AutoCAD, polylines and circles measured these elements from each photograph. Aggressive automobile facilities include any feature added to the streetscape that augments the role of cars or caters to motorists, in particular: traffic signs or lights, gas stations, parking lots, and billboards. Last, rejecting objects include any permanent or semi-permanent feature that is part of the streetscape and detracts from the sense of security, hospitality, and friendliness of the street. Examples include: poor-quality graffiti, large dumpsters, and low-quality light poles. Each 

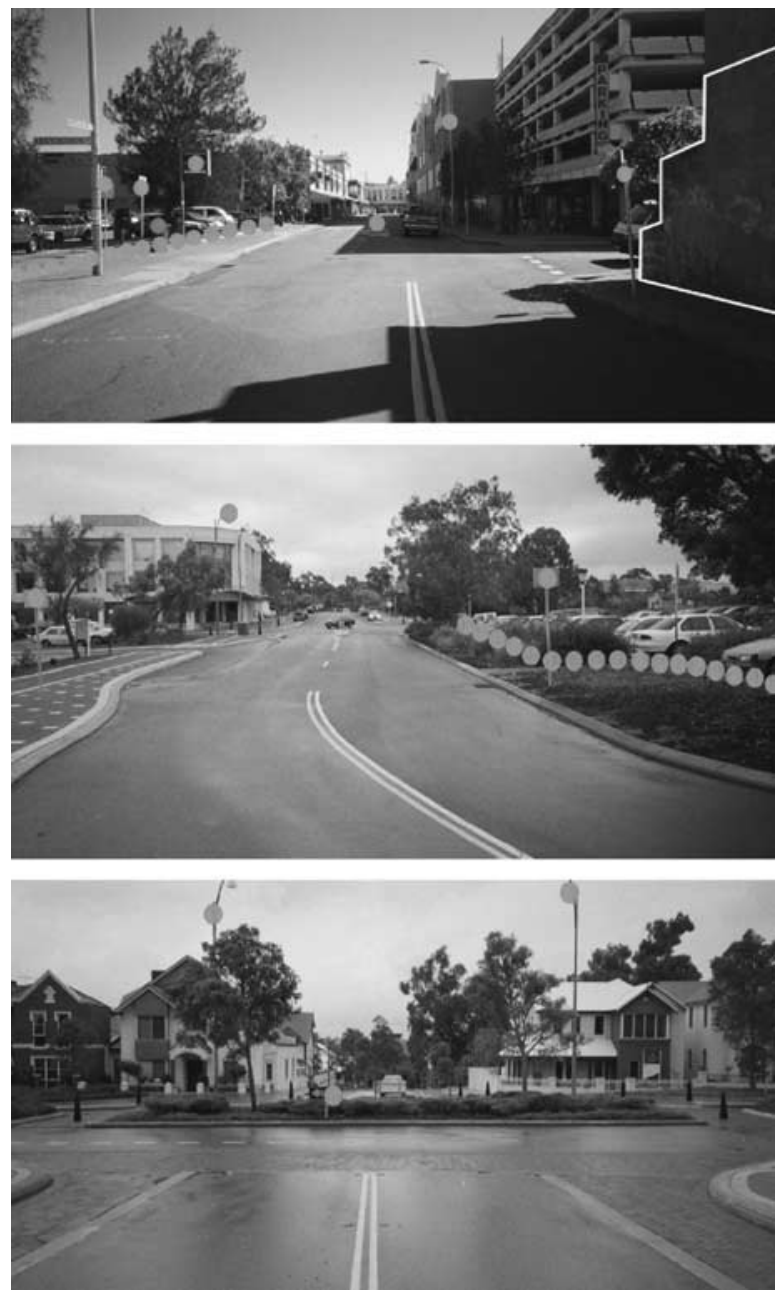

Figure 10. Street indicators: samples of detractors from the higher (top) to the lower (bottom).

sub-indicator was normalized before calculating the average (see Figure 10).

\section{Results of the field research in Western Australia: Fremantle and Joondalup}

Urban fabric and street indicators were processed in order to produce maps and a database of the two cases. Using AutoCAD and ArcVIEW, the database was linked to polygons on maps of Joondalup and Fremantle. The resulting graphics were used for developing the first of the four layouts of the study: the photo-by-photo maps of each street indicator (Figure 11). These layouts allow for an in-depth, indicator-by-indicator comparison of the two cases. The study of every single street may also take advantage of the detailed description provided with this layout.

In the photo-by-photo maps - the first layout - the legend was built on an average-and-standarddeviation basis: blues show value below the average, reds above the average.

The same was then done for the second layout: the street-by-street table. This analysis (see Figure 12) allows for a quick evaluation of the performance of each street, on average, for each indicator: this helps to highlight strengths and weaknesses of each street or groups of streets and leads to a better understanding of general trends.

Next, the third layout was a set of pie-charts (Figure 13) based on data of each indicator with reference to the whole case. This allows for a very effective understanding of the overall character of the two cases as well as of the main differences between them.

Finally, a cluster analysis was used on the photoby-photo database (Figure 14) aimed at grouping together data, which resulted similar when all the eight street indicators are simultaneously considered. That led to the fourth layout: a sort of zoning map that eases the linking of highlighted weaknesses and strengths to specific areas of the two urban fabrics. This seems to be crucial for the aim of targeting the right policies to the right places.

\section{Conclusion: the relevance of the formal indicators concept and tools}

A large gap was detected between Fremantle and Joondalup. Despite the valuable strategies and guidelines used to design the new town of Joondalup, the traditional, late-Victorian urban fabric of Fremantle fairs superior. In particular, the streets of Joondalup came out to be simply too large to work well in social terms; moreover, a sort of 'withdrawal of the city from the city's scene' was recognized in Joondalup, where very often the borders of the streets do not show the presence of buildings, lined trees, shops or the clues of any human activity.

The indicators allowed for a number of detailed observations pointing at several specific spots 

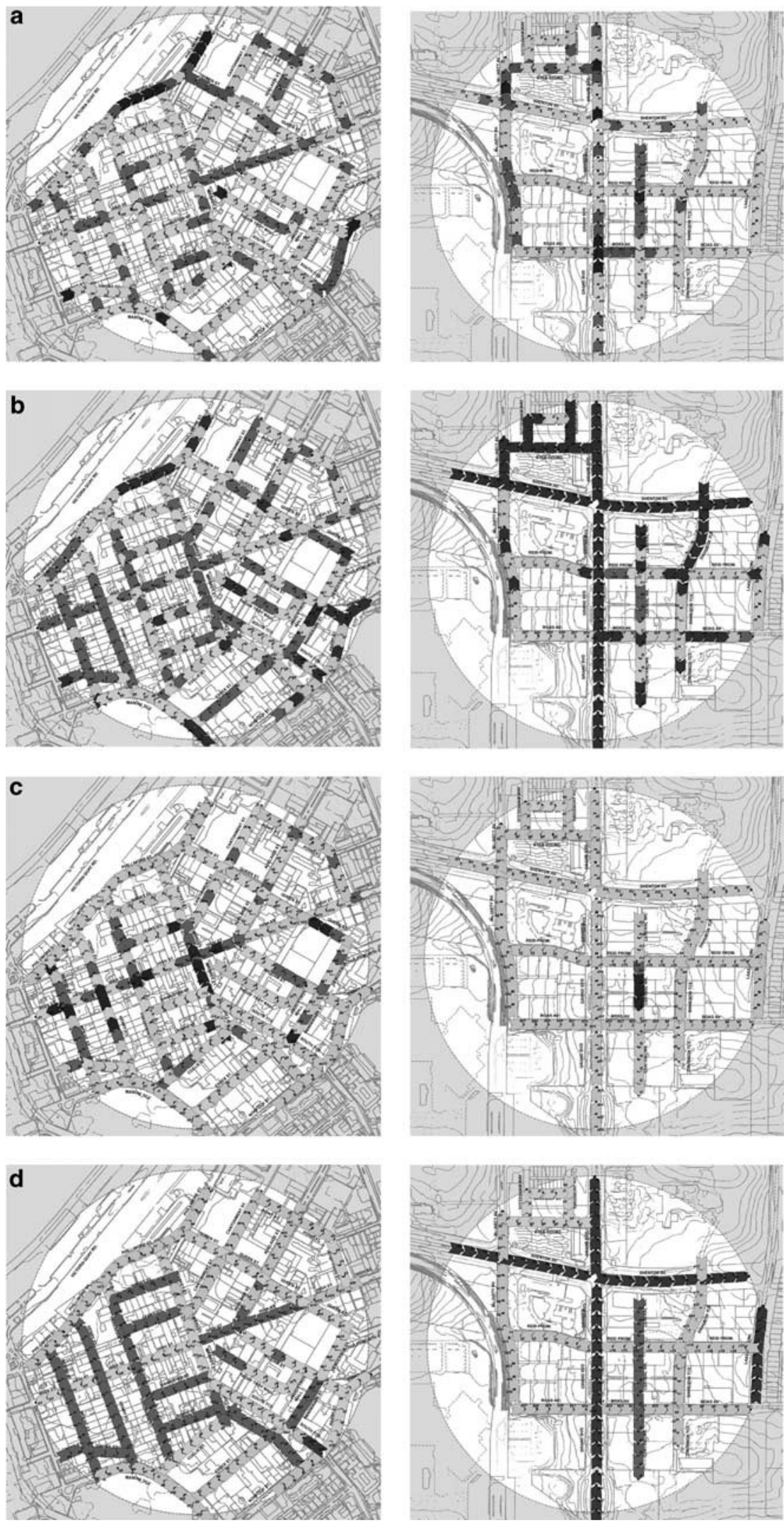

Figure 11. Street indicators, samples of Layout 1 'Photo-by-photo map'. (a) Sky exposure in Fremantle (left) and Joondalup (right). (b) Façade continuity in Fremantle (left) and Joondalup (right). (c) Softness in Fremantle (left) and Joondalup (right). (d) Social width in Fremantle (left) and Joondalup (right). 


\begin{tabular}{|c|c|c|c|c|c|c|}
\hline \multirow{2}{*}{ Indicator } & \multicolumn{2}{|c|}{ All Streets } & \multicolumn{2}{|c|}{ Central Streets } & \multicolumn{2}{|c|}{ Main Streets } \\
\hline & Fremantle & hoondalup & Fremantle & loondalup & Fremantle & Ioondalup \\
\hline Sky Expasare & & & & & & \\
\hline Facade continu & & & & & & \\
\hline Soltiness & & & & & & \\
\hline $\begin{array}{l}\text { Social Width } \\
\text { Vitumi Complex }\end{array}$ & & & & & & \\
\hline Number of build & & & & & & \\
\hline Sedibility & & & & & & \\
\hline
\end{tabular}

Fremantle

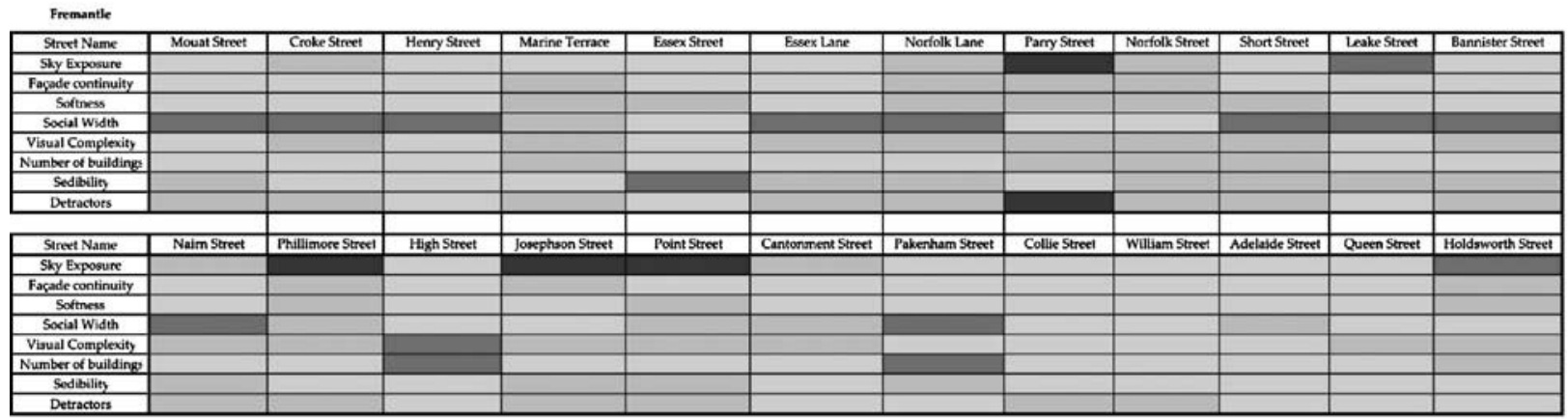

\begin{tabular}{|c|c|c|c|c|}
\hline Struet Name & Paddy Troy Mall & Market Street & South Terrace & Henderson Street \\
\hline Sky Fxposure & & & & \\
\hline \multicolumn{5}{|l|}{ Facade continuity } \\
\hline \multicolumn{5}{|l|}{ Sotiness } \\
\hline \multicolumn{5}{|l|}{ Soxial Width } \\
\hline \multicolumn{5}{|l|}{ Visual Complexity } \\
\hline \multirow{2}{*}{\multicolumn{5}{|c|}{$\frac{\text { Number of building }}{\text { Sediblity }}$}} \\
\hline & & & & \\
\hline Detractors & & & & \\
\hline
\end{tabular}

Figure 12. Street indicators, samples of Layout 2 'Street-by-street table': groups of streets (top) and the case of Fremantle (bottom).
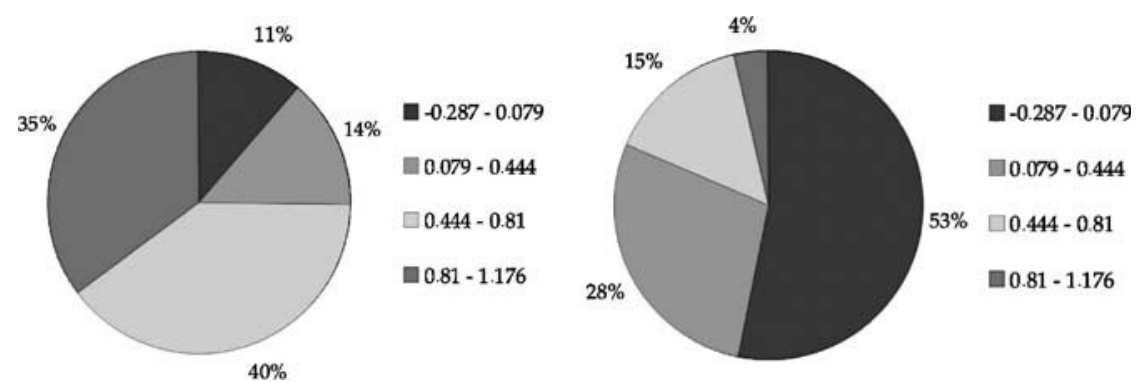

Figure 13. Street indicators, samples of Layout 3 'Pie charts': Façade continuity in Fremantle (left) and Joondalup (right).

within the two cities, and issues related to local conditions were discussed to improve upon the urban form. In particular, large institutional locations in Joondalup seem to be designed in a manner that works against, rather than for the city, while Fremantle still needs to develop a strategy for urban parking lots and multistory parking. In both cases, a specific policy for diffusing sedibility resulted to be strongly needed, even if Fremantle does show the presence of some very sedible spots like the 'cappuccino strip'.

Results of the four layouts helped to draw both general and specific conclusions. The general lessons, which were summarized as the 10 'rules of thumb' for designing sustainable streets of the future, were drawn as follows (this applies to mostly to downtown areas or commercial centers, but may have applicability in other parts of the city as well):

1. Design streets as narrow as possible (to accommodate the pedestrian over the automobile).

2. Do not isolate buildings (especially institutional buildings) in lots; buildings should line the streets.

3. Do not allow setbacks: building fronts should be as continuous as possible along the street. 


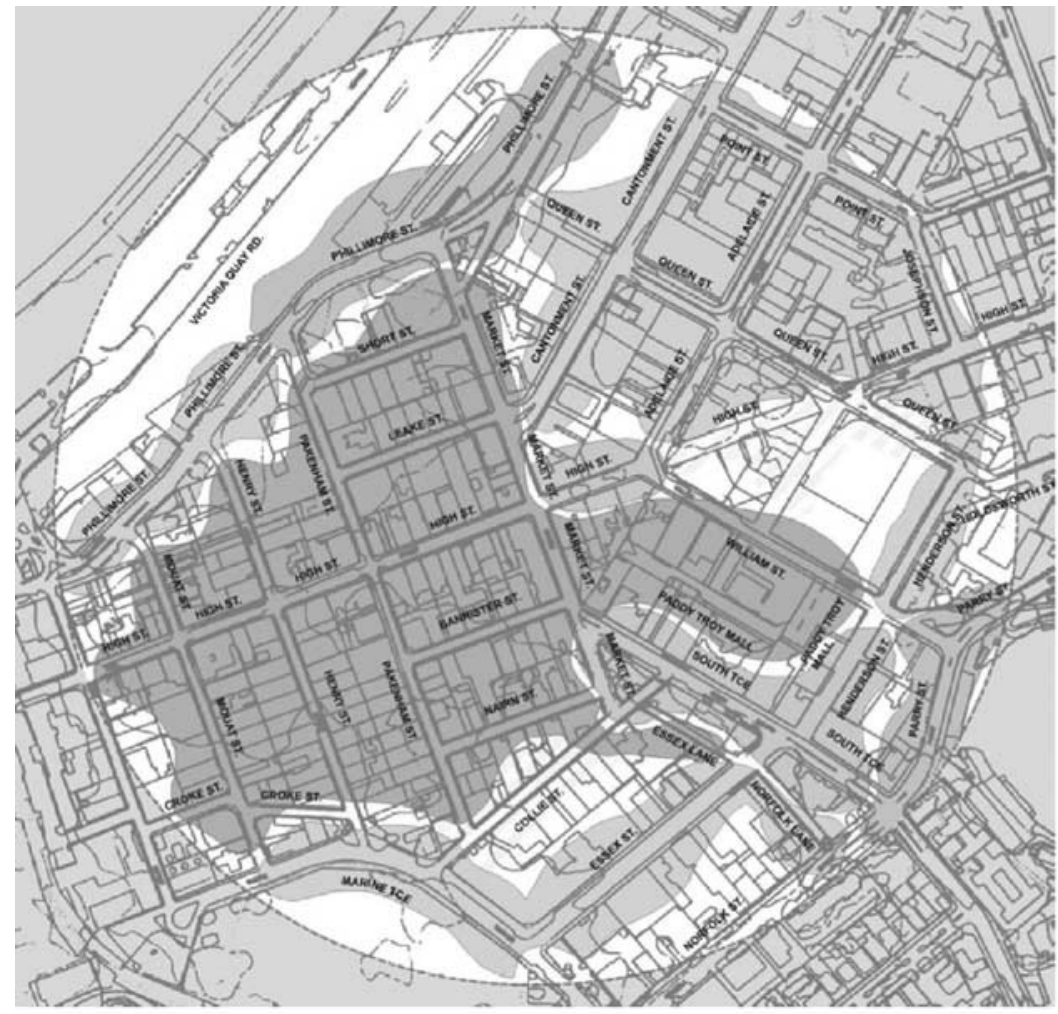

Compact City

"Soft" Compact City

"Border" City

"Ghost" City

Mixed City

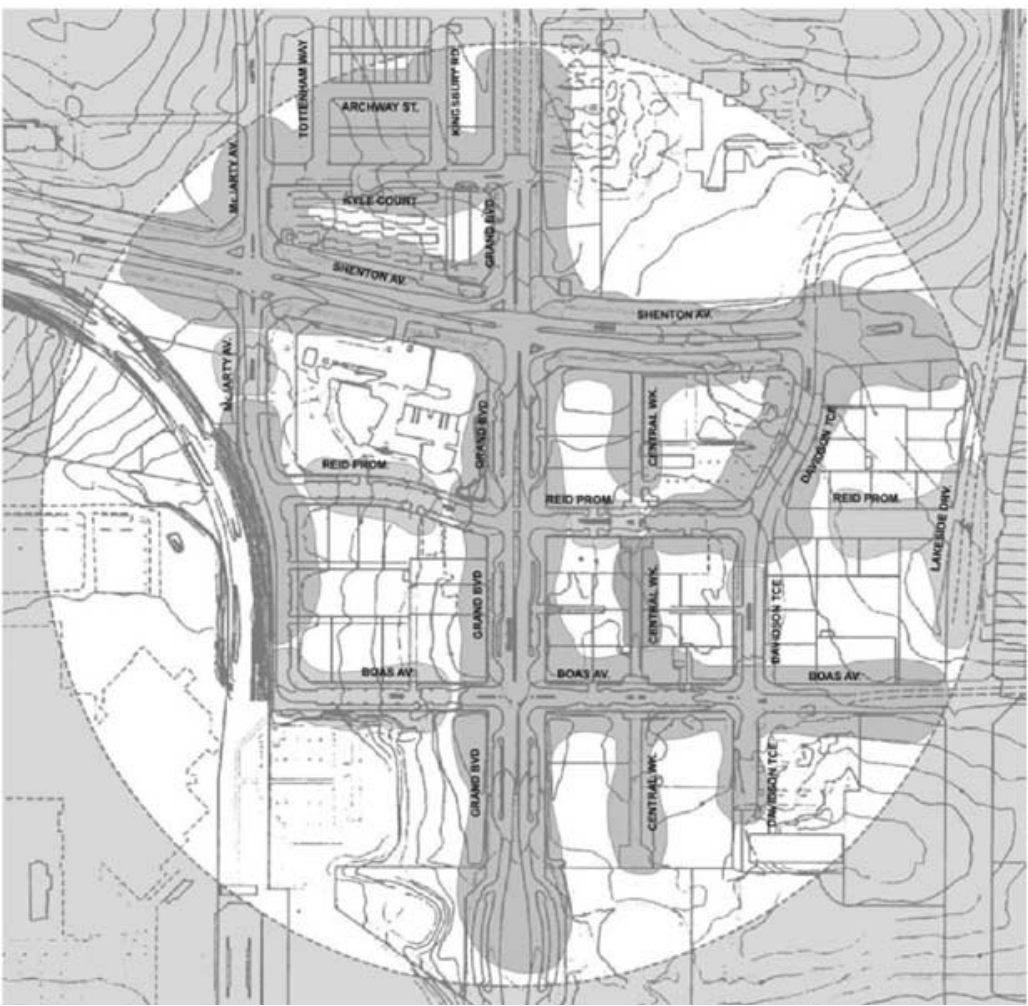

Figure 14. Street indicators, samples of Layout 4 'Cluster analysis': zoning maps of Fremantle (top) and Joondalup (bottom). 
4. Make many small buildings instead of few large ones.

5. Design retail at the ground floor wherever possible.

6. Avoid parking lots: on-street parking is much better; even multistory parking is better, provided that retail is located at the ground floor facing the street and the façade of the parking deck is disguised to blend into the architectural environment.

7. Design porticos, arcades, low fencing, stoops, shelters and the like: everything that can provide a soft transition from the street to the building is crucial.

8. Avoid blank walls. Avoid large billboards, traffic lights, large on-street trash dumpsters, high light poles, but especially: avoid blank walls!

9. Put trees on wide streets: trees are very often the only thing we can do for making existent streets more lively and friendly, but they can make a big difference.

10. Places for sitting are all-important: provide sedible arrangements wherever possible.

The formal indicators analysis developed for the comparison of Fremantle and Joondalup proved to be highly descriptive of the urban environment at the microlevel of the neighborhood (commercial center) and the street. It allowed for an in-depth understanding of some formal characteristics of the urban fabric, which in many ways can be related to the social sustainability of places. Moreover, it highlighted relevant differences in the physical settings of the two cases, which are generally under-represented in the political agenda as well as in the planning debate and in the social awareness of the local community. Policies can be undertaken to better the social value of urban places using strategies of urban design. A renovated attention needs to be paid to the contextualization of large institutional buildings, the strengths and interconnectivity of street layout, the visual communication between street fronts, the sedibility of public space, the use of a tree canopy to reach a better level of intimacy on (sub) urban streets, the negative impact of parking lots and blank walls and the like. Moreover, those policies can be tracked in time to keep the progressing of their implementation under the social control of local communities. SDIs can be the first step in bridging the gap between urban design and truly achieving sustainability with quantitative measures.

\section{References}

Gehl, J. (1987) Life between Buildings: Using Public Space. New York: Van Nostrand Reinhold.

Goffman, E. (1963) Behavior in Public Places; Notes on the Social Organization of Gathering. New York: Free Press of Glencoe.

Goffman, E. (1967) Interaction Ritual; Essays in Face-toface Behavior. Chicago: Aldine Publishing Company.

Jacobs, J. (1961) The Death and Life of Great American Cities. New York: Random House.

Lemert, C. and Branaman, A. (eds.) (1997) The Goffman Reader. Cambridge, MA: Blackwell.

Ministry for Planning. (2001) Sustainable Urban Design: Practical Fieldwork Project. Booklet presented at the 'Sustainable Urban Design Course' 2001, ISTP, Murdoch University, Perth, WA.

Newman, O. (1973) Defensible Space: Crime Prevention through Urban Design. New York: Collier Books.

Newman, O. (1996) Creating Defensible Space. US Department of Housing and Urban Development, Office of Policy Development and Research, Washington, DC, USA.

Whyte, W.H. (1988) City: Rediscovering the Center. New York: Doubleday.

\section{Further Reading}

Bosselmann, P. (1998) Representation of Places: Reality and Realism in City Design. Berkeley, CA: University of California Press.

Cooper-Marcus, C. and Sarkissian, W. (1986) Housing as if People Mattered: Site Design Guidelines for MediumDensity Family Housing. Berkeley, CA: University of California Press.

Gehl, J. (1977) Interface between Public and Private Territories in Residential Areas, Department of Architecture and Building. Melbourne: Melbourne University.

Gehl, J. (1994) Public Spaces and Public Life in Perth. Perth: Report for the Government of Western Australia and the City of Perth.

Gehl, J. and Gemzøe, L. (1996) Public Spaces Public Life. Copenhagen: Arkitektens Forlag.

Gehl, J. and Gemzøe, L. (2000) New City Spaces. Copenhagen: The Danish Architectural Press.

Jacobs, A. (1993) Great streets. Boston, MA: MIT Press.

Jacobs, A. and Bosselmann, P. IDS 241: best students works at Jacobs and Bosselmann's IDS 241 course, UCB Berkeley: Patel B., Chiao C.S., Jung Chin I. 1985. Memorable Street. December 1985; Hilken H., Nagle K., Rosenberg M., Sadik R. 1987. Memorable Residential Streets. Fall 1987; Bergdoll J., Williams R.W. 1988. A study of Perceived Density. Fall 1988; 
Gambetti F., Wolfe M., Broudehoux A.M. 1996. Elements of Street Memorability: a Study of Grant and Stockton Streets in san Francisco's Chinatown. Fall 1996.

Southworth, M. and Ben-Joseph, E. (1997) Streets and the Shaping of Towns and Cities. New York: McGrawHill.
Ramati, R. (1981) How to Save your own Street. New York: Doubleday.

Vernez-Moudon, A. (ed.) (1987) Public Streets for Public Use. New York : Van Nostrand Reinhold.

Whyte, W.H. (1980) The Social Life of Small Urban Spaces. Washington, DC: The Conservation Foundation. 